\title{
Increased Bite Distance From the Edge Lowers Risk of Pullout of Simple Sutures from Acellular Dermal Allograft
}

\author{
Chad D. Hanson, D.O., Jay C. Thompson, D.O., Jake X. Checketts, D.O., \\ David P. Beason, M.S., Craig Pille, M.S., and Lawrence Lemak, M.D.
}

\begin{abstract}
Purpose: To investigate whether pullout strength in the acellular dermal allograft matrix (ADM) used for superior capsule reconstruction depends on the distance from the edge of the graft. Methods: ADM used for superior capsule reconstruction was obtained and cut into 30 squares. Two sutures were placed through the center of each graft by using a loaded Keith needle and forming a simple stitch. The grafts were divided into 3 groups of 10 grafts with a distance of 5 $\mathrm{mm}, 10 \mathrm{~mm}$ or $15 \mathrm{~mm}$ from the closest edge of the graft, respectively. The grafts were then preloaded to $5 \mathrm{~N}$ and pulled to failure at a rate of $12 \mathrm{~mm} / \mathrm{s}$ on an MTS 858 MiniBionix servohydraulic mechanical test frame. The load to failure was recorded as well as the stiffness of each graft. Results: The mean load to failure was $34.5 \mathrm{~N}$ (SD 7.89 ) for the 5 mm grafts, $31.7 \mathrm{~N}$ (SD 5.99) for the $10 \mathrm{~mm}$ grafts, and 66.2 N (SD 18.4) for the $15 \mathrm{~mm}$ grafts. There was a significant difference $(<0.0001)$ between the large grafts $(15 \mathrm{~mm})$ and the 2 smaller grafts $(10 \mathrm{~mm}, 5 \mathrm{~mm})$. There was no significant difference in stiffness between the groups of graft $(P 0.40)$. Conclusion: Placing the suture at least $15 \mathrm{~mm}$ from the edge of the graft increases the graft's ultimate yield strength to suture pullout. Clinical Relevance: The depths of the suture in ADM could improve pullout strength for constructs of superior capsular reconstructions.
\end{abstract}

$\mathbf{M}$ assive rotator cuff tears are difficult to treat because of high failure rates, even after surgical management. ${ }^{1}$ Tendon transfers and direct repairs carry a $52 \%$ recurrence rate, and reverse total shoulder arthroplasty studies have shown satisfactory results in the older population, but subjects were not matched to younger patients. ${ }^{2}$

Superior capsule reconstruction (SCR) has become a newer treatment option for massive rotator cuff tears. Originally described using a fascia lata autograft, surgeons have now proposed dermal allograft matrix (ADM) for its reliable elongation properties, faster surgical times and elimination of donor-site morbidity. ${ }^{3}$

From the Oklahoma State University Medical Center, Department of Orthopaedic Surgery (C.D.H., J.C.T., J.X.C.), Tulsa, Oklahoma; and American Sports Medicine Institute, Lemak Health (D.P.B., C.P., L.L.), Birmingham, Alabama, U.S.A.

The authors report no conflicts of interest, and this work was not funded. Full ICMJE author disclosure forms are available for this article online, as supplementary material.

Received December 12, 2020; accepted June 29, 2021.

Address correspondence to Jay C. Thompson, 1111 West 17th Street, Tulsa, OK 74107 U.S.A.E-mail: jay.thompson@okstate.edu

(C) 2021 THE AUTHORS. Published by Elsevier Inc. on behalf of the Arthroscopy Association of North America. This is an open access article under the CC BY-NC-ND license (http://creativecommons.org/licenses/by-nc-nd/4.0/). 2666-061X/201917

https://doi.org/10.1016/j.asmr.2021.06.015
Major complications have been cited as being tears or pullouts of grafts, which the literature has shown can range from a $3.4 \%$ to a $55 \%$ tear rate with allograft reconstructions. $^{4-6}$ There have been biomechanical studies that investigated the pullout strength in relation to the graft thickness as well as glenoid suture configuration. ${ }^{7,8}$ However, little is known about the distance from the edge of the graft and the placement of the suture. With more than 29 different surgical techniques for SCR, we limited as many variables, such as suture configuration and location, as possible and tested the inherent properties of the ADM. ${ }^{9}$

The purpose of this study was to investigate whether pullout strength in the ADM used for superior capsule reconstruction depended on the distance from the edge of the graft. Our hypothesis was that the deeper the suture was placed into the graft $(5 \mathrm{~mm}, 10 \mathrm{~mm}$ or 15 $\mathrm{mm})$, the stronger the ultimate yield of the graft to suture pullout would be, based on previous biomechanical studies with suture pullout in fascial planes. ${ }^{10}$

\section{Methods}

\section{Graft Preparation}

Four ADM grafts were obtained that were $40 \mathrm{~mm} \mathrm{x}$ $70 \mathrm{~mm}$ and had a graft thickness of $1.4 \mathrm{~mm}$. The grafts 


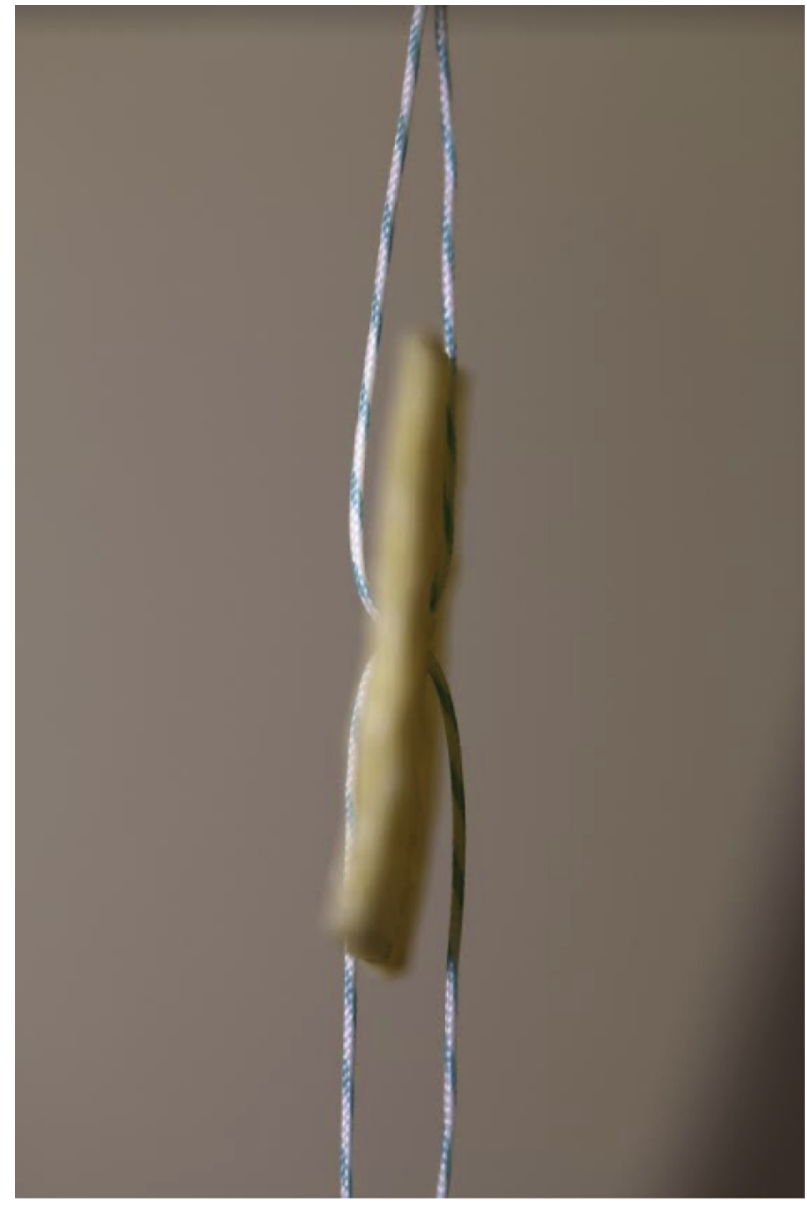

Fig 1. Image of graft preparation with \#2 FiberLoop stitch through dermal allograft matrix (ADM).

were measured and cut into $10 \mathrm{~mm}, 20 \mathrm{~mm}$ and $30 \mathrm{~mm}$ squares using sharp scissors. Ten squares were made of each size. Once cut, the grafts were fully hydrated in normal saline according to factory specifications (DermaSpan, Biomet Orthopedics, Warsaw, IN). Each graft then had an 18-gauge spinal needle placed through the center of the graft to create enough space for the straight needle and loop braided \# 2 suture (FiberLoop) to pass. Once the loop was passed through the graft, the needle was cut off and the loop cut into 2 equal strands, forming a simple stick stitch (Fig 1).

\section{Biomechanical Analysis}

Each graft was placed on an MTS 858 MiniBionix servohydraulic mechanical test frame (MTS Systems, Eden Prairie, MN) and secured to a suture plate using a loop stitch with screws (Fig 2). The grafts were all preloaded to a force of $5 \mathrm{~N}$ and then pulled at a rate of $12 \mathrm{~mm} / \mathrm{s}$ until graft failure and suture pullout. Graft failure was defined by complete suture pullout through the ADM. The ultimate load just prior to failure and the stiffness of each graft were recorded. All 30 graft samples were placed through the mechanical test frame in the same fashion. ANOVA was used to compare the 3 groups, and the Tukey post hoc test was used to compare specific pairs of groups.

\section{Results}

For the suture placed $5 \mathrm{~mm}$ from the edge of the $\mathrm{ADM}$, the mean ultimate load was $34.3 \mathrm{~N}$ (SD 7.89, $95 \%$ CI 5.36) to suture pullout. At $10 \mathrm{~mm}$ and $15 \mathrm{~mm}$, the mean ultimate load to failure was $31.7 \mathrm{~N}$ (SD 5.99, $95 \%$ CI 4.29) and $66.2 \mathrm{~N}$ (SD 18.4, 95\% CI 13.20), respectively, with the ANOVA $P$ value $-0.0000004^{*}$ compared with one another. All grafts sustained suture pullout for mode of failure.

A Tukey post hoc test showed significant difference between the $5 \mathrm{~mm}$ and the $15 \mathrm{~mm}$ group $\left(P\right.$ value $\left.-0.00002^{*}\right)$ and between the $10 \mathrm{~mm}$ and 15 $\mathrm{mm}$ group $\left(P\right.$ value $\left.-0.00001^{*}\right)$ but not in the $5 \mathrm{~mm}$ and $10 \mathrm{~mm}$ group ( $P$ value-0.202) in regard to ultimate yield $(\mathrm{N})$. The stiffness of the $5 \mathrm{~mm}, 10 \mathrm{~mm}$ and $15 \mathrm{~mm}$ sutured grafts was not significantly different, with mean values of $10.9 \mathrm{~N} / \mathrm{mm}$ (SD 2.60), $9.46 \mathrm{~N} / \mathrm{mm}$ (SD 3.06) and $10.8 \mathrm{~N} / \mathrm{mm}$ (SD 2.33$)$, respectively ( $P$ value -0.400$)$ (Table 1) (Fig 3).

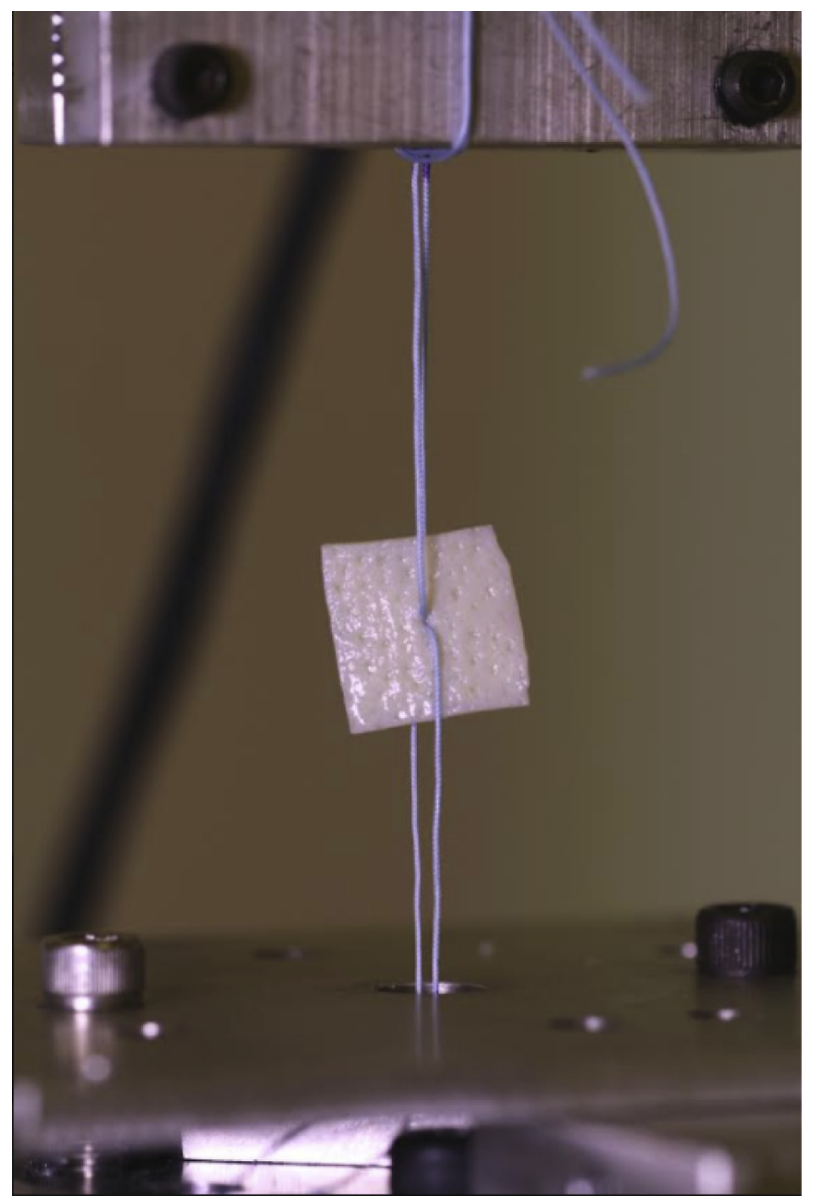

Fig 2. Image of biomechanical apparatus during testing. 
Table 1. Results of Ultimate Load and Stiffness Based on Suture Depth

\begin{tabular}{lcc}
\hline & Ult. Load & $\frac{\text { Stiffness }}{(\mathrm{N} / \mathrm{mm})}$ \\
\cline { 2 - 3 } & $(\mathrm{N})$ & \\
\hline $5 \mathrm{~mm}$ & 34.3 & 10.9 \\
Mean & 7.98 & 2.60 \\
SD & $23 \%$ & $24 \%$ \\
Cov & & \\
$10 \mathrm{~mm}$ & 31.7 & 9.46 \\
Mean & 5.99 & 3.06 \\
SD & $19 \%$ & $32 \%$ \\
Cov & & \\
$15 \mathrm{~mm}$ & 66.2 & 10.8 \\
Mean & 18.4 & 2.33 \\
SD & $28 \%$ & $21 \%$ \\
Cov & $0.0000004^{*}$ & 0.400 \\
$P$ value (ANOVA) & & \\
\hline
\end{tabular}

*Indicates significant results based on anova.cov $=$ coefficienct of variation -ratio of standard deviation to the mean.

\section{Discussion}

In our study, the sutures placed $15 \mathrm{~mm}$ from the edge of the ADM had a significantly higher ultimate yield to suture pullout than those placed $<15 \mathrm{~mm}$ to the edge. Our data's suture pullout strength was 31-66 N, which is comparable to similar ADM biomechanical studies such as that of Stilwell and Stevens, whose Allomend ADM demonstrated a suture pullout of 62-124 N, and Adelman et al., whose porcine ADM measured a maximum load average of $61.55 \pm 15.66 \mathrm{SD}^{8,11} \mathrm{In}$ biomechanical cadaveric studies, Barber et al. ${ }^{12}$ demonstrated that rotator cuffs augmented with ADM were $325 \mathrm{~N}$ compared to the $273 \mathrm{~N}$ nonaugmented control group. This study provides a reference that the $\mathrm{ADM}$ alone accounts for a roughly $52 \mathrm{~N}$ increase in suture pullout, which is comparable to our data's suture-pullout strength. ${ }^{12}$

We believe our study offers some clinical relevance in multiple ways. In various clinical outcomes papers for SCR with ADM, the authors found complication rates/ tears ranging from $3.4 \%$ to $55 \% .^{4-6}$ First, placing the sutures at $15 \mathrm{~mm}$ from the graft edge significantly increases the strength of the construct. Second, we believe more graft will increase the surface area for the graft to incorporate and heal. In their discussion, Denard et al. credited the high tear rate from the humeral side of the graft as being due to increased stresses compared with the glenoid. They noted that graft healing was associated with higher functional outcomes. $^{4}$

The strength of this study was finding that stiffness is not significantly different ( $P$ value -0.400$)$ in the 3 groups. All 3 groups were made by the same graft manufacturer with the same specifications, so the grafts were biomechanically similar (DermaSpan). There were no failures due to suture failure or slippage, thus allowing maximum efficiency in allograft usage. One curious finding was that the $5 \mathrm{~mm}$ suture depth's ultimate load $(34.3 \mathrm{~N}$ [SD 7.89, 95\% CI 5.36]) was higher than that of the $10 \mathrm{~mm}$ depth $(31.7 \mathrm{~N}$ [SD $5.99,95 \% \mathrm{CI}$ 4.29]); however, this was justified because there was no statistically significant ( $P$ value -0.202 ) difference between the groups. That the stiffness was similar among the 3 groups provides support for the findings that the strongest construct against suture pullout needs at least $15 \mathrm{~mm}$ of suture depth to be significant.

\section{Limitations}

The weaknesses of the study include the limited supply of the ADM. The limited access to the graft allowed only the use of grafts with $1.4 \mathrm{~mm}$ thickness, which is thin compared to the other grafts available on the market. Because of the cost of the allograft, the amount and groups were maximized, but a $20 \mathrm{~mm}$ group may have added some clinical relevance. The ADM was also cut into squares, which limits its clinical correlation because the grafts are usually formed as a rectangle or trapezoid when used clinically. Also, we evaluated only l vendor's allograft, although various others are on the market. This biomechanical model demonstrates effects only on suture pullout on the graft with a simple stick stitch; it can not account for stitch configuration, type of suture (i.e., suture tape) or other modes of suture failure. Last, other studies have cited elasticity and deformity after cycling as a mode of failure of the ADM. In our study, the ADM was not cycled, which may be considered a weakness. ${ }^{13}$

\section{Conclusion}

Placing the suture at least $15 \mathrm{~mm}$ from the edge of the graft increases the graft's ultimate yield strength to suture pullout. More studies would be necessary to determine clinical significance.

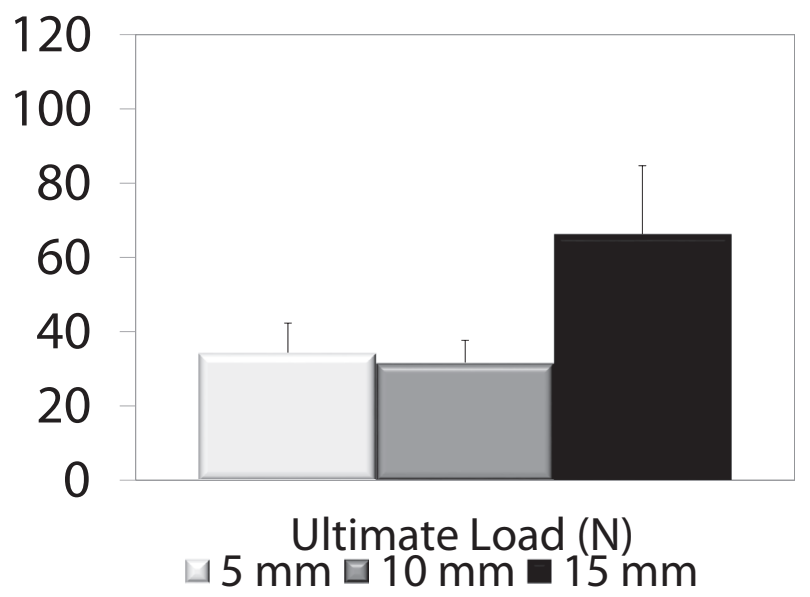

Fig 3. Ultimate load in newtons of acellular graft pullout. $5 \mathrm{~mm}=$ $34.3 \pm 7.98 ; 10 \mathrm{~mm}=31.7 \pm 5.99 ; 15 \mathrm{~mm}=66.2 \pm 18.4$. 


\section{References}

1. Henry P, Wasserstein D, Park S, et al. Arthroscopic repair for chronic massive rotator cuff tears: A systematic review. Arthroscopy 2015;31:2472-2480.

2. Tokish JM, Makovicka JL. The superior capsular reconstruction: Lessons learned and future directions. J Am Acad Orthop Surg 2020;28:528-537.

3. Pogorzelski J, Muckenhirn KJ, Mitchell JJ, et al. Biomechanical comparison of 3 glenoid-side fixation techniques for superior capsular reconstruction. Am J Sports Med 2018;46:801-808.

4. Denard PJ, Brady PC, Adams CR, Tokish JM, Burkhart SS. Preliminary results of arthroscopic superior capsule reconstruction with dermal allograft. Arthroscopy 2018;34: 93-99.

5. Pennington WT, Bartz BA, Pauli JM, Walker CE, Schmidt W. Arthroscopic superior capsular reconstruction with acellular dermal allograft for the treatment of massive irreparable rotator cuff tears: Short-term clinical outcomes and the radiographic parameter of superior capsular distance. Arthroscopy 2018;34:1764-1773. doi:10. 1016/j.arthro.2018.01.009.

6. Andersen WJ, Panero AAJ. Superior capsular reconstruction: Clinical outcomes after minimum 2-year follow-up. Am J Orthop 2017;46:266-272.
7. Mihata T, McGarry MH, Kahn T, Goldberg I, Neo M, Lee TQ. Biomechanical role of capsular continuity in superior capsule reconstruction for irreparable tears of the supraspinatus tendon. Am J Sports Med 2016;44: 1423-1430. doi:10.1177/0363546516631751.

8. Stilwell R, Stevens PJ. The biomechanics of AlloMend acellular dermal matrix: Ultimate tensile strength. pacmedical.com. https://pacmedical.com/wp-content/up loads/2018/11/AlloMend-Suture-Retention.pdf.

9. Gao I, Sochacki KR, Freehill MT, Sherman SL, Abrams GD. Superior capsular reconstruction: A systematic review of surgical techniques and clinical outcomes. Arthroscopy 2021;37:720-746.

10. Campbell JA, Temple WJ, Frank CB, Huchcroft SA. A biomechanical study of suture pullout in linea alba. Surgery 1989;106:888-892.

11. Adelman DM, Selber JC, Butler CE. Bovine versus porcine acellular dermal matrix: A comparison of mechanical properties. Plast Reconstr Surg Glob Open 2014;2:e155.

12. Barber FA, Herbert MA, Boothby MH. Ultimate tensile failure loads of a human dermal allograft rotator cuff augmentation. Arthroscopy 2008;24:20-24.

13. Omae H, Steinmann SP, Zhao C, et al. Biomechanical effect of rotator cuff augmentation with an acellular dermal matrix graft: A cadaver study. Clin Biomech 2012;27:789-792. 